\title{
NOTE ON THE EARLIER WORK ON LEPROSY ()F DR. ERNEST MUIR.
}

\author{
LEONARD Rogers.
}

It was in 1920 that Dr. E. Muir accepted the post of wholetime research worker in leprosy in the newly founded Calcutta School of Tropical Medicine. The work was financed by an endowment fund which I had raised to provide for five additional research units. 
In 1916 and I9I7 I published, with coloured drawings and photos before and after treatment, very promising results in comparatively early cases of leprosy by the injection of soluble preparations of chaulmoogra oils, in place of the inefficient agelong oral use of these nauseating drugs. Muir at once took up the new method of treatment and was the first to confirm my work. I turned to him, therefore, as the best qualified man to continue my leprosy research in India when I went home on leave early in I920 preparatory to retirement under the age rules.

Leprosy is a disease which shows such great variations in type, symptomology, degrees of mildness and severity and in its prolonged course, that only patient and prolonged investigations could allow the limits of the value of the improved method of treatment to be determined, and further technical improvements in the use of soluble chaulmoogra preparations to be worked out. Moreover, owing to the then small amount of interest of the medical profession in such an apparently hopeless disease as leprosy, no-one had any idea of its real incidence in India and other afflicted countries and its earlier stages were little known. How then were the earlier cases, which alone I had found to be amenable to treatment, to be discovered and induced to attend dispensaries for long periods for treatment?

These and other difficult problems awaited the attention of the newly constituted leprosy research unit in Calcutta. The following account will show how efficiently they were tackled by Muir and his assistants.

Muir's early work in Calcutta was mainly on two lines: firstly, further technical improvements in the use of chaulmougra preparations for the injection treatment: and secondly, extensive surveys in selected areas to determine the true incidence of leprosy in India and to ascertain the most practical methods of extending the treatment of early cases of leprosy with a view to the ultimate control and reduction of the disease.

I had mainly used intramuscular and intravenous injections of weak solutions of the sodium salts of the lower melting points fatty acids of hydnocarpus wightiana oil. Its intravenous use was handicapped by its irritant effect causing blocking of the veins, but Muir got over the difficulty by the simple expedient of diluting the solution by drawing up some blood into the syringe before injecting the whole. A more important advance resulted from his finding that pure fresh hydnocarpus oil was unirritating when injected intramuscularly with a little creosote as an antiseptic. Both methods are very cheap, as compared with the use of ethyl esters of chaulmoogra oil, introduced in I9I9 by American 
workers in Hawaii, although the latter is very useful by intradermal injection into the skin lesions.

Muir and his assistants also carried out comprehensive house to house surveys for cases of leprosy in selected areas in each province of India with a total of two and a half million people examined. On comparing the data so obtained with the census figures for the same areas, which only included very advanced cases easily recognised at a glance by non-medical enumerators, they thus showed that when the early cases were included the true number amounted to four and a half times those returned at the last census. The proportion has since been placed by some as high as ten times. Fortunately some four-fifths of the early cases proved to be of nerve type, which are little, if at all, infective. They can therefore be treated as out-patients without being isolated. This patient enquiry enabled Muir to formulate his Propaganda-SurveyTreatment plan, under which the confidence of the people is first obtained by instructing them on the subject, house to house surveys are then carried out to disclose the true prevalence of the disease and special leprosy dispensaries are opened under doctors trained for the purpose at the Calcutta school. Within a few years hundreds of such clinics were opened all over India at which scores of thousands of early amenable cases were treated, and the people were also instructed on house isolation of infective cases in the villages. I had also advocated early in I920 the establishment in every province of India of agricultural colonies for voluntary isolation, with adequate treatment, of the more highly infective nodular, or as they are now called, lepromatous cases; but lack of funds has prevented much advance in this essential feature of leprosy prohylaxis except in Madras.

Muir also availed himself of the abundant clinical material attending his Calcutta leprosy out-patient department to describe the phases and stages of the disease and especially its early little known stages. In the meantime I had spent three years in England on a comprehensive study of the literature of leprosy for some six decades, to ascertain the conditions favouring the spread of the disease and the most practical methods of its control. I then enlisted Muir's help in writing the clinical and pathological sections cf a book on leprosy, to which I contributed sections on its history and distribution, epidemiology and communicability and on prophylaxis. This appeared in I925 and reached a third edition in I946; and it has influenced progress throughout the Britich Empire and far beyond it. In I924 the British Empire Leprosy Relief Association was founded in Lonclon, and as the result of a visit to India in 1925 of its first Secretary, Mr. Frank Oldrieve, Lord 
Reading, the then Viceroy, issued an appeal for an Indian branch. The success of this appeal enabled the Indian fund to take over financial responsibility for the Leprosy Research section of the Calcutta School of Tropical Medicine and for work in every province of India. 